\title{
Inflammatory Hepatocellular Adenoma
}

National Cancer Institute

\section{Source}

National Cancer Institute. Inflammatory Hepatocellular Adenoma. NCI Thesaurus. Code C96760.

A hepatocellular adenoma that occurs more often in women. It is characterized by increased levels of inflammation-associated proteins. It is usually associated with steatosis and obesity. 